\title{
Contribuição para o projeto de biofiltros aplicados ao tratamento de emissões odorantes provenientes de reatores anaeróbios
}

\author{
Contribution to the design of biofilters applied to the \\ treatment of odorous emissions from anaerobic reactors
}

Carlos Augusto de Lemos Chernicharo (*)

Professor Associado do Departamento de Engenharia Sanitária e Ambiental da UFMG.

\section{Richard M. Stuetz}

Professor Associado da University of New South Wales Sydney - Austrália

\section{Cláudio Leite Souza}

Doutorando do Programa de Pós-graduação em Saneamento, Meio Ambiente e Recursos Hídricos da Escola de Engenharia da UFMG

Gilberto Caldeira Bandeira de Melo

Professor Associado do Departamento de Engenharia Sanitária e Ambiental da UFMG.

Endereço para correspondência (*):

Departamento de Engenharia Sanitária e Ambiental - UFMG; Av. do Contorno, 842/7 ${ }^{\circ}$ andar - Centro - Belo Horizonte MG - CEP: 30110-060 - Brasil - Tel: (31) 3409-1020 - e-mail: calemos@desa.ufmg.br

\section{RESUMO}

A presente nota técnica busca consolidar importantes aspectos relacionados ao tratamento biológico de emissões odorantes, com ênfase à aplicação de biofiltros para o controle de sulfeto gerado em reatores anaeróbios. São apresentados os principais pontos de emissão de sulfeto em reatores UASB, bem como as principais alternativas e métodos para o controle de tais emissões, com destaque para a aplicabilidade dos biofiltros. São ilustradas as configurações usuais de biofiltros e apresentados os princípios do tratamento biológico de odores. Por fim, são consolidadas as principais diretrizes para o projeto de biofiltros aplicados ao tratamento de emissões odorantes provenientes de reatores anaeróbios tratando esgoto doméstico.

\section{ABSTRACT}

This technical note aims at consolidating important aspects regarding biological treatment of odorous emissions, focusing the application of biofilter for the control of sulfide generated in anaerobic reactors. The main emission sources of odorants in UASB reactors are presented, as well as the main alternatives and methods for controlling these emissions, highlighting the applicability of biofilters. Typical biofilter configurations are illustrated and the principles of biological odour treatment are presented. Finally, the main guidelines for the design and operation of biofilters applied to the treatment of odorous emissions from anaerobic reactors treating domestic wastewater are consolidated.

PALAVRAS-CHAVE: biofiltro, emissões odorantes, reatores anaeróbios, sulfeto de hidrogênio

KEY-WORDS: anaerobic reactors, biofilter, hydrogen sulfide, odorous emissions

\section{INTRODUÇÃO}

De acordo com a experiência brasileira (CHERNICHARO \& STUETZ, 2008), as possíveis melhorias relacionadas a projeto, construção e operação de reatores UASB aplicados ao tratamento de esgoto doméstico podem ser agrupadas de acordo com os tópicos mostrados na Figura 1. Embora melhorias para todos os tópicos mostrados na referida figura estejam correntemente sendo investigadas, no presente trabalho são enfocadas apenas as melhorias relacionadas ao tratamento das emissões odorantes. As emissões odorantes que criam problemas em estações de tratamento de esgotos, durante o tratamento da fase líquida, relacionam-se principalmente aos compostos de enxofre, notadamente o sulfeto de hidrogênio (H2S), uma vez que os limites de percepção olfatória para este composto ocorre em concentrações muito baixas (5 ppbv). Compostos nitrogenados e outros compostos, como ácidos graxos voláteis (AGV), aldeídos e cetonas, são uma preocupação secundária nas unidades de tratamento da fase líquida (WEF, 2004). Nas unidades de tratamento da fase sólida, no entanto, outros compostos que não o H2S são os principais responsáveis pelas emissões odorantes.

Conforme mostrado na Figura 1, as emissões odorantes podem estar relacionadas à fase gasosa (biogás e gases residuais) e à fase líquida (afluente e efluente). Dessa forma, diferentes estratégias são necessárias para se controlar essas emissões, dependendo das suas fontes, conforme mostrado na Tabela 1. 


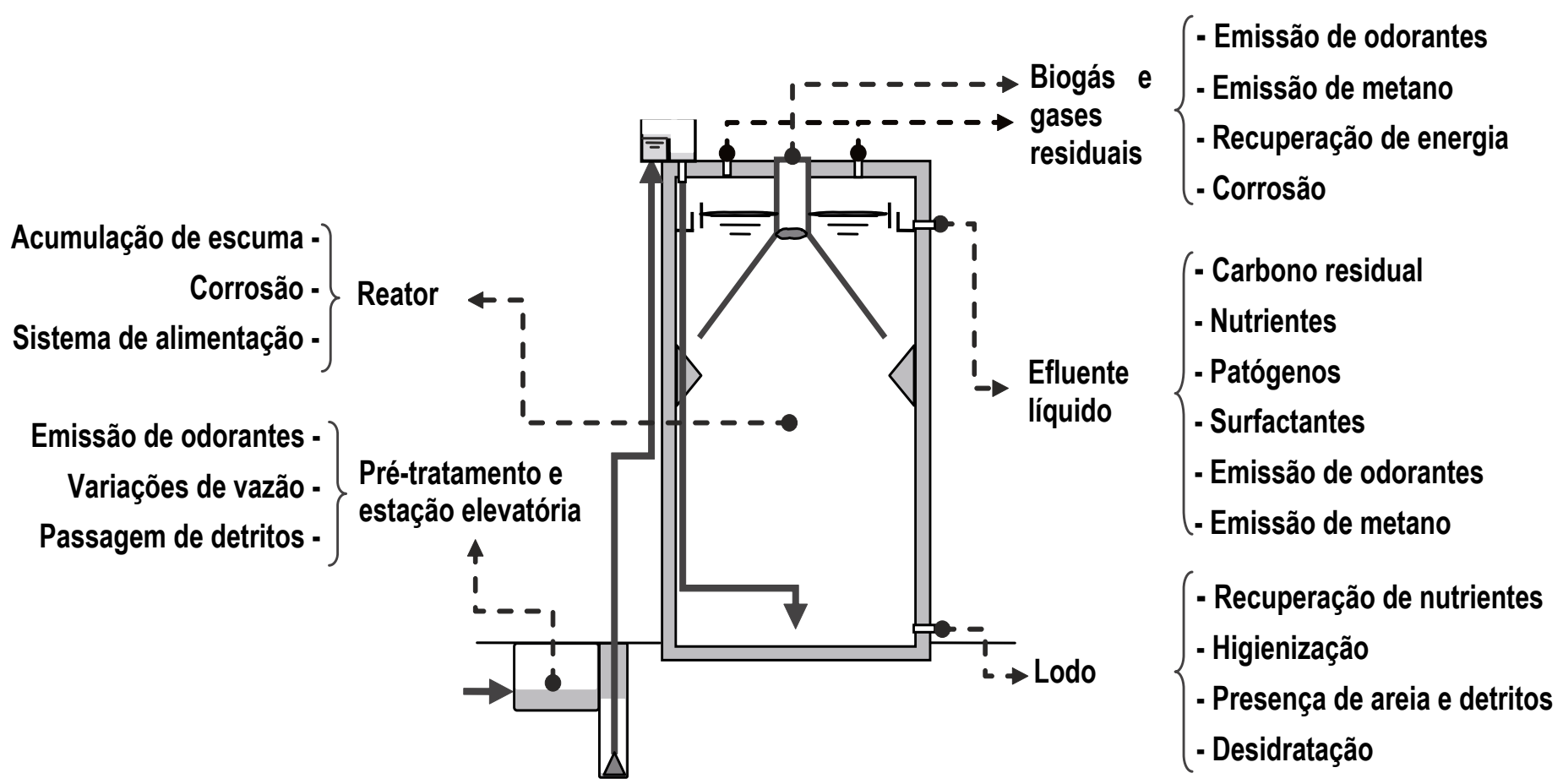

Figura 1: Tópicos de interesse para possíveis melhorias em ETEs que empregam reatores UASB

A presença de $\mathrm{H}_{2} \mathrm{~S}$ no afluente é totalmente dependente das características do esgoto e do sistema de coleta e transporte, a exemplo do comprimento, da declividade e da ventilação, não tendo qualquer relação com o processo de tratamento. Em relação ao $\mathrm{H}_{2} \mathrm{~S}$ gerado nos reatores UASB, este pode se apresentar dissolvido na fase líquida ou ser liberado para a fase gasosa. As frações de $\mathrm{H}_{2} \mathrm{~S}$ que estarão presentes nas fases líquida e gasosa dependerão de fatores como $\mathrm{pH}$, temperatura, pressão parcial do gás e grau de turbulência na fase líquida. $\mathrm{O} \mathrm{H}_{2} \mathrm{~S}$ que se libera da fase líquida ainda no interior do reator poderá estar presente tanto no biogás coletado pelo separador trifásico quanto no gás residual liberado na superfície do compartimento de decantação. A quantidade de $\mathrm{H}_{2} \mathrm{~S}$ emitida pela superfície do decantador depende essencialmente do tipo de dispositivo de coleta do efluente, sendo maior no caso de canaletas com vertedores e menor no caso de tubos submersos perfurados. Adicionalmente, poderão ocorrer emissões ainda mais substanciais de $\mathrm{H}_{2} \mathrm{~S}$ ao longo dos canais e tubulações de transporte do efluente, a depender do grau de turbulência existente na saída do reator anaeróbio e no percurso até a unidade de pós-tratamento ou até o lançamento final.

\section{APLICABILIDADE E PRINCÍPIO DE FUNCIONAMENTO DOS BIOFILTROS}

Conforme tratado em Chernicharo et al. (2010), embora existam diversos métodos bioquímicos para o tratamento de odores, os biofiltros se mostram como a alternativa mais apropriada para o abatimento de compostos odorantes presentes nos gases residuais de reatores anaeróbios tratando esgoto doméstico, uma vez que, nestes casos, o principal composto odorante motivo de preocupação é o $\mathrm{H}_{2} \mathrm{~S}$, usualmente presente em baixas concentrações ( 0 a $500 \mathrm{ppm})$, portando, na faixa ideal de atuação dos biofiltros. De acordo com van Groenestijn \& Hesselink (1993) e Kennes \& Thalasso (1998), os biofiltros são mais indicados para o tratamento de gases odorantes com concentrações de $\mathrm{H}_{2} \mathrm{~S}$ abaixo de abaixo de 1,0 g.m $\mathrm{m}^{-3}$ (aproximadamente $687 \mathrm{ppm}$ ). Ademais, são sistemas que agregam as maiores vantagens em termos de simplicidade, sustentabilidade e baixos custos de construção e de operação. Nos biofiltros, o gás odorante é forçado através de um meio suporte, no qual microrganismos ficam aderidos na forma de um biofilme. Os compostos voláteis biodegradáveis são absorvidos/adsorvidos pelo meio suporte e pelo biofilme, sendo biologicamente oxidados a substâncias menos prejudiciais, como $\mathrm{CO}_{2}, \mathrm{H}_{2} \mathrm{O}, \mathrm{NO}_{3}$ - e $\mathrm{SO}_{4}^{2}$-. $\mathrm{O}$ oxigênio, necessário como aceptor de elétrons, é usualmente fornecido continuamente pelo próprio fluxo de gás residual. $\mathrm{O}$ meio suporte é tipicamente composto de material orgânico (carvão, turfa, sabugo de milho, bagaço de cana, cavaco, casca e apara de madeira, composto etc.), todavia a utilização de material inorgânico (como solo e areia) tem aumentado muito nos últimos anos. Outras substâncias requeridas pelos microrganismos (nutrientes e elementos traço) são lentamente liberadas pelo meio suporte de característica orgânica, ou então fornecidos juntamente com a água de irrigação, no caso de meio suporte inorgânico (VAN GROENESTIJN \& HESSELINK, 1993).

Outra importante característica do processo é a ausência de uma fase líquida móvel, embora o fluxo de gás residual e o meio suporte sejam umidificados para facilitar a atividade microbiana. A ausência de uma fase líquida móvel limita o 
controle operacional, fazendo com que maiores volumes de meio suporte sejam necessários para se garantir o adequado tempo de residência dos gases odorantes. Como conseqüência, os biofiltros são também apropriados para o tratamento de compostos odorantes pouco solúveis em água (KENNES \& THALASSO, 1998).

Tabela 1: Principais alternativas para o controle de H2S em estações de tratamento de esgoto

\begin{tabular}{|c|c|c|c|}
\hline Fonte da emissão & $\begin{array}{c}\text { Tipo de } \\
\text { tratamento }\end{array}$ & Possibilidades & Principais métodos \\
\hline & $\begin{array}{l}\text { Tratamento da } \\
\text { fase gasosa }\end{array}$ & -Tratamento dos compostos odorantes & $\begin{array}{l}\text {-Biofiltros ou outros métodos de tratamento } \\
\text { de } \mathrm{H}_{2} \mathrm{~S}\end{array}$ \\
\hline Esgoto afluente & $\begin{array}{l}\text { Tratamento da } \\
\text { fase líquida }\end{array}$ & $\begin{array}{l}\text {-Utilização de medidas para controlar os } \\
\text { compostos odorantes antes que sejam } \\
\text { emitidos }\end{array}$ & $\begin{array}{l}\text {-Adicionar ar ou oxigênio a montante da } \\
\text { estação } \\
\text {-Adição de produtos químicos para } \\
\text { interromper a produção de sulfeto ou para } \\
\text { reagir com o sulfeto na massa líquida }\end{array}$ \\
\hline Biogás & $\begin{array}{l}\text { Tratamento da } \\
\text { fase gasosa }\end{array}$ & $\begin{array}{l}\text { - Oxidação térmica dos compostos } \\
\text { odorantes juntamente com o metano } \\
\text {-Tratamento seletivo do } \mathrm{H}_{2} \mathrm{~S} \mathrm{e} \\
\text { recuperação do metano para fins } \\
\text { energéticos }\end{array}$ & $\begin{array}{l}\text { - Combustão direta ou outros métodos de } \\
\text { oxidação térmica e catalítica } \\
\text { - Métodos físicos, químicos e bioquímicos de } \\
\text { tratamento }\end{array}$ \\
\hline $\begin{array}{l}\text { Gases residuais de } \\
\text { reatores } \\
\text { anaeróbios }\end{array}$ & $\begin{array}{l}\text { Tratamento da } \\
\text { fase gasosa }\end{array}$ & -Exaustão, coleta e tratamento do $\mathrm{H}_{2} \mathrm{~S}$ & $\begin{array}{l}\text {-Biofiltros ou outros métodos de tratamento } \\
\text { de } \mathrm{H}_{2} \mathrm{~S}\end{array}$ \\
\hline Efluente anaeróbio & $\begin{array}{l}\text { Tratamento da } \\
\text { fase líquida }\end{array}$ & $\begin{array}{l}\text {-Pós-tratamento aeróbio do efluente } \\
\text { anaeróbio } \\
\text {-Stripping em estrutura de dissipação, } \\
\text { seguido de coleta e tratamento do } \mathrm{H}_{2} \mathrm{~S}\end{array}$ & $\begin{array}{l}\text {-Lodos ativados, biofiltros aerados } \\
\text { submersos, biodiscos, lagoas facultativas e } \\
\text { aeróbias, inclusive lagoas de polimento e de } \\
\text { maturação } \\
\text { - Biofiltros ou outros métodos de tratamento } \\
\text { de } \mathrm{H}_{2} \mathrm{~S}\end{array}$ \\
\hline
\end{tabular}

\section{BIOQUÍMICA DO TRATAMENTO BIOLÓGICO DE ODORES}

Os poluentes orgânicos e inorgânicos presentes nos gases residuais são tratados biologicamente por microrganismos heterotróficos ou por microrganismos autotróficos. Os organismos heterotróficos utilizam compostos orgânicos para suprir as suas necessidades tanto de energia como de carbono, enquanto os organismos autotróficos utilizam compostos inorgânicos como fonte de energia, enquanto o carbono para crescimento celular é obtido a partir do gás carbônico.

Os organismos autotróficos obtêm energia a partir de compostos inorgânicos à base de nitrogênio (como amônia [NH3], íon amônio [NH4+] e nitrito [NO2-]), à base de enxofre (como sulfeto de hidrogênio [H2S], sulfeto [HS-]) e, em alguns casos, à base de ferro. Uma vez dentro da célula, a energia é extraída a partir de processos metabólicos específicos e um subproduto oxidado do composto é liberado (WEF, 2004). No caso particular do H2S, o enxofre é utilizado por espécies bacterianas a exemplo das pertencentes ao gênero Thiobacillus, que liberam ácido sulfúrico [H2SO4] como subproduto. Este, por sua vez, é responsável pela corrosão de superfícies de concreto e de metal expostas ao sulfeto de hidrogênio nos sistemas de esgotamento sanitário.

Devido à sua habilidade em rapidamente utilizar compostos inorgânicos, os métodos biológicos de controle de odor utilizam microrganismos autotróficos para remover compostos inorgânicos como H2S e NH3. Alguns organismos autotróficos também podem degradar determinados compostos orgânicos de baixo peso molecular (a exemplo do bissulfeto de carbono, metilmercaptanas e etilmercaptanas), mas nesses casos apenas os grupos funcionais de enxofre são degradados, deixando as ligações carbono-carbono intactas (WEF, 2004).

Tipos e principais características

Os biofiltros podem ser classificados em três tipos principais:

i) biofiltro não estruturado e com enchimento de fundo (Fig. 2); ii) biofiltro estruturado e sem enchimento de fundo (Fig. 3);

iii) biofiltro pré-fabricado (Fig. 4).

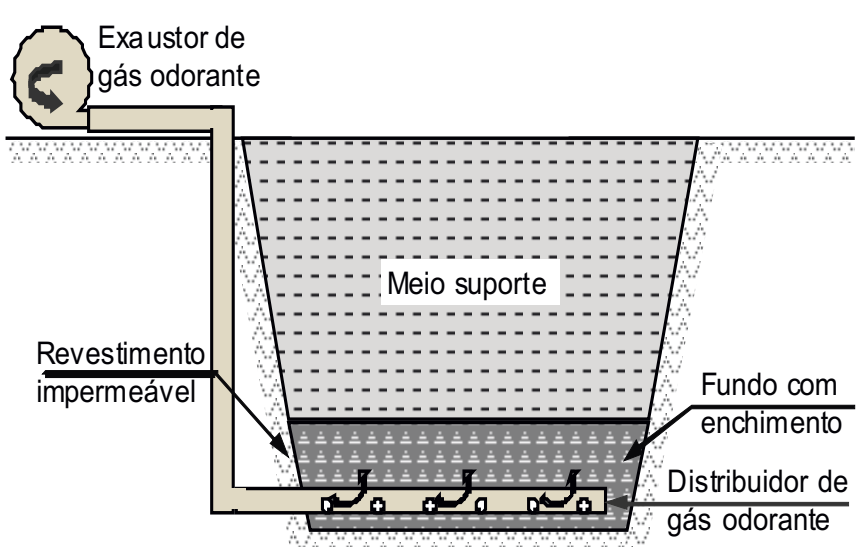

Figura 2: Configuração esquemática de um biofiltro não estruturado e com enchimento de fundo 


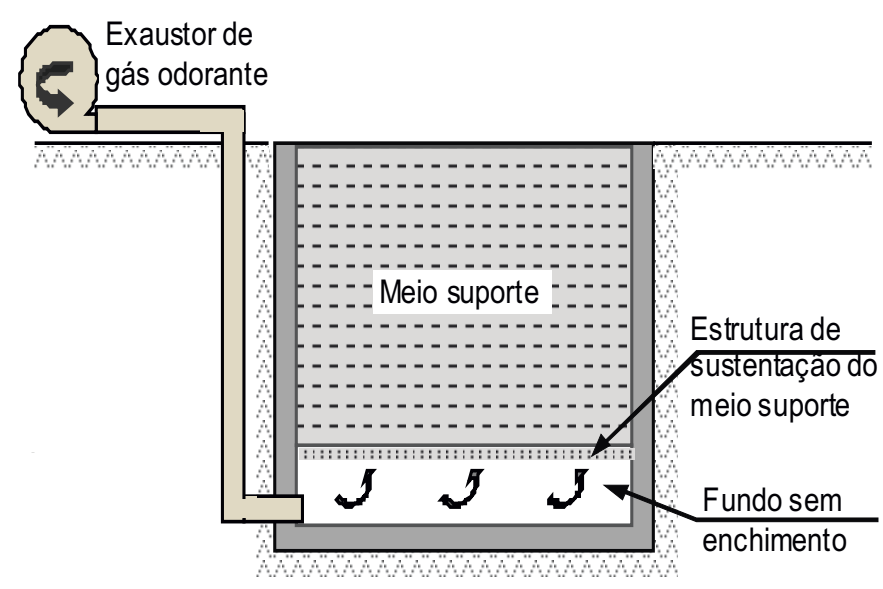

Figura 3: Configuração esquemática de um biofiltro estruturado e sem enchimento de fundo

Os biofiltros são compostos das seguintes partes:

i) tubulação de admissão de gases e sistema de exaustão;

ii) fundo falso;

iii) sistema de drenagem de fundo;

iv) estrutura de sustentação do meio suporte;

v) meio suporte;

vi) sistema de irrigação do meio suporte.

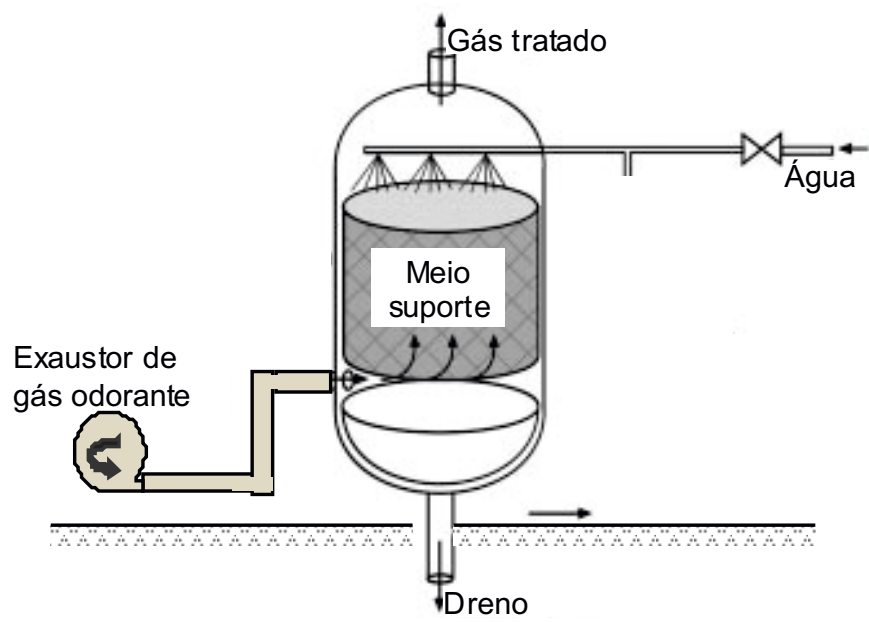

Figura 4: Configuração esquemática de um biofiltro pré-fabricado

As principais diretrizes e recomendações para o projeto e a operação de biofiltros aplicados ao tratamento de odores gerados em estações de tratamento de esgoto são mostradas na Tabela 2.

Parte do biofiltro de admissão de gases e sistema de exaustão

\section{Diretriz/recomendação}

- Todos os materiais e equipamentos devem ser resistentes à corrosão pelo ácido sulfúrico a 10\%. Tipicamente, os seguintes materiais são utilizados: PVC, PEAD e fibra de vidro;

- As velocidades dos gases nos trechos de tubulação aparente não devem exceder a $8 \mathrm{~m}^{-1} \mathrm{~s}^{-1}$ a fim de evitar ruído e perda de carga excessivos;

- Preferencialmente, devem ser utilizados exaustores centrífugos com impelidores contra-inclinados, confeccionados em fibra de vidro. As pressões usuais de trabalho situam-se entre 12 e $500 \mathrm{~mm}$.c.a., para perdas de carga através de camadas típicas de meio suporte orgânico da ordem de $10 \mathrm{~mm}$.c.a., no início de operação do biofiltro, a $250 \mathrm{~mm}$.c.a., ou mais, quando se aproxima o final de vida útil do meio suporte. Exaustores de fluxo axial e sopradores de deslocamento positivo não são usualmente utilizados, por apresentarem limitações de pressões mínimas e máximas, além da possibilidade de fuga de emissões odorantes no caso dos exaustores de fluxo axial;

- Os exaustores devem possuir ponto de purga, de modo a possibilitar a drenagem de todo o condensado que se acumular no interior de sua carcaça.

- Os biofiltros devem ser minimamente equipados com medidores de vazão e manômetros, em cada tubulação de distribuição de gás no fundo do filtro.

- 0 fundo falso dos biofiltros pode ser aberto ou preenchido com material de enchimento. No caso de fundos falsos abertos deve-se prever uma estrutura de sustentação para o meio suporte. Nos fundos falsos preenchidos, a tubulação de distribuição de gases fica envolta pelo material de enchimento;

- Em ambos os tipos de fundo falso, tanto a estrutura de sustentação quanto o material de enchimento devem ser resistentes à corrosão pelo ácido sulfúrico a $10 \%$;

Fundo falso - No caso de fundos falsos preenchidos, é importante que a maior parte da perda de carga em todo o sistema de coleta e distribuição seja através dos furos na tubulação de distribuição, a fim de garantir a aplicação equitativa dos gases em toda a superfície do meio suporte;

- Tipicamente, os furos na tubulação de distribuição são feitos na metade inferior da tubulação, alinhados a $45^{\circ} \mathrm{com}$ a vertical. 0 tamanho e o espaçamento entre furos são determinados em função da vazão de gases e perda de carga necessária. Adicionalmente, devem ser previstos furos na parte inferior das tubulações principais de distribuição, espaçados de $1,0 \mathrm{~m}$, para possibilitar a drenagem do líquido condensado.

- As paredes laterais e de fundo do biofiltro devem ser devidamente impermeabilizadas, de modo a possibilitar que toda a água excedente da irrigação e do condensado sejam coletados pelo sistema de drenagem de fundo. Mantas de PEAD com espessura mínima de $1500 \mu \mathrm{m}$ são usualmente utilizadas no caso de biofiltros não estruturados com enchimento de fundo.

Sistema de drenagem de

fundo

- Toda a água acumulada no fundo do biofiltro deve ser coletada e encaminhada de volta a alguma unidade do sistema de tratamento da fase líquida. A alcalinidade do esgoto é usualmente suficiente para neutralizar o ácido sulfúrico presente no líquido drenado do biofiltro. Caso não seja, deverá ser feita a neutralização prévia do líquido drenado. 
Estrutura de sustentação do meio suporte irrigação do meio suporte

- No caso de biofiltros com fundo falso aberto, a estrutura de sustentação deve ser rígida e dimensionada para suportar todo o peso do meio suporte e do biofilme, sem deformação. Lajes perfuradas de concreto armado e placas de material plástico são usualmente utilizadas para esse fim, todavia devem ser revestidas ou feitas de material resistente à corrosão ao ácido sulfúrico a $10 \%$.

- No caso de biofiltros com fundo falso preenchido, é recomendável a utilização de seixo rolado de sílica como material de enchimento.

- Os meios suportes devem ser possuir uma camada inferior (camada 3 - Quadro 1) constituída de materiais inorgânicos que resistam às condições ácidas provocadas pela oxidação do $\mathrm{H}_{2} \mathrm{~S}$ e formação de ácido sulfúrico, e uma camada superior (camada 4 - Quadro 1), constituída de uma mistura homogênea de material orgânico e material inorgânico, de modo a prover os nutrientes necessários aos microrganismos.

- No Quadro 1 são apresentadas características típicas para as camadas de enchimento de biofiltros não estruturados (Fig. 2). A camada 2 é inexistente no caso de biofiltros estruturados sem enchimento de fundo (Fig. 3), podendo existir ou não nos biofiltros pré-fabricados (Fig. 4). A camada 5 é inexistente no caso de biofiltros pré-fabricados (Fig. 4), podendo existir ou não no caso de biofiltros estruturados sem enchimento de fundo (Fig. 3).

- 0 meio suporte deve ser mantido com umidade adequada, a fim de possibilitar condições ambientais favoráveis ao crescimento dos microrganismos oxidadores dos compostos odorantes. Todavia, o excesso de umidade pode provocar a criação de zonas anaeróbias e aumentar o peso unitário do material de enchimento. Teores típicos de umidade requeridos para o meio suporte são da ordem de 40 a $60 \%$, em peso, para a camada superior (material orgânico) e 20 a 50\%, em peso, para a camada inferior (material inorgânico). 0 próprio efluente tratado da ETE pode ser utilizado para prover a umidade necessária ao biofiltro, já que este é uma excelente fonte de nutrientes para os microrganismos.

- A altura do meio suporte do biofiltro (camadas 3 e 4 - Quadro 1) deve estar compreendida entre 0,80 e 1,20 m.

- As perdas de carga no meio suporte do biofiltro devem ser mantidas entre 10 e $250 \mathrm{~mm}$ de coluna de água.

- No dimensionamento do equipamento de exaustão dos gases residuais devem ser considerados os seguintes parâmetros: i) taxa de renovação de gases do volume correspondente ao headspace da câmara de gases residuais entre 4 e 5 por hora; ii) pressão negativa no interior da câmara de gases residuais da ordem de $1 \mathrm{a} 2 \mathrm{~mm}$.c.a. Consideram-se gases residuais aqueles que se desprendem da fase líquida durante o tratamento do esgoto, seja no interior do compartimento de decantação de reatores UASB, no interior das estruturas de dissipação, notadamente de efluentes anaeróbios, ou em qualquer outro local da ETE onde ocorra o desprendimento de gases odorantes. Considera-se volume de headspace aquele compreendido entre a superfície da lâmina líquida e a parte superior da câmara de gases residuais.

- 0 meio suporte deve ser mantido com umidade adequada, a fim de possibilitar o crescimento e o estabelecimento dos microrganismos oxidadores dos compostos odorantes. Para tanto, são usualmente utilizados dois tipos de sistemas de irrigação: subsuperficial e superficial.

- O sistema de irrigação subsuperficial é mais eficiente, por possibilitar o fornecimento de umidades diferenciadas ao longo da profundidade do biofiltro, de acordo com as necessidades do meio suporte e dos microrganismos. Usualmente são utilizadas mangueiras perfuradas a cada $50 \mathrm{~cm}$, uma posicionada a $15 \mathrm{~cm}$ acima do fundo falso e outra a $60 \mathrm{~cm}$. As diferentes zonas são preferencialmente irrigadas em horários diferentes.

- A irrigação superficial é conseguida basicamente por meio de aspersores de jardim. Devem ser utilizados com rigor, uma vez que o excesso de irrigação pode supersaturar a camada superior do biofiltro, o que pode prejudicar a circulação de gases, provocar 0 aumento da perda de carga e favorecer a compactação prematura do meio. Taxas de irrigação usuais situam-se entre 20 e $30 \mathrm{~L} \cdot \mathrm{m}^{-2} . \mathrm{d}^{-1}$.

Fonte: Adaptado de WEF (2004)

Quadro 1: Caracterização das camadas de enchimento de um biofiltro

\begin{tabular}{|c|c|c|c|c|}
\hline \multirow{6}{*}{ 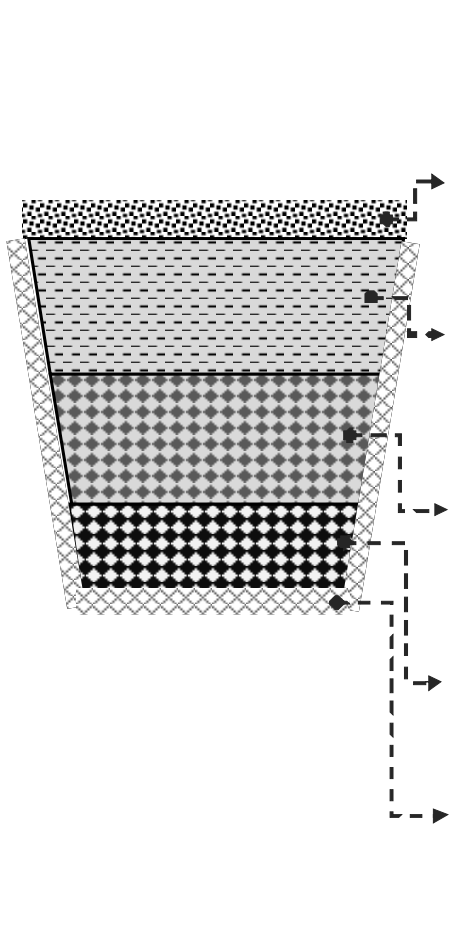 } & Camada & $\begin{array}{l}\text { Espessur } \\
\mathrm{a}(\mathrm{cm})\end{array}$ & Composição & Finalidade \\
\hline & $\begin{array}{c}5 \\
\text { (camada } \\
\text { superficial) }\end{array}$ & 10 a 15 & $75 \%$ terra $+25 \%$ adubo & Plantio de cobertura vegetal \\
\hline & $\begin{array}{c}4 \\
\text { (meio suporte } \\
\text { orgânico) }\end{array}$ & 30 a 50 & $\begin{array}{l}\text { Mistura homogênea ( } 20 \% \text { solo } \\
\text { ou areia }+40 \% \text { composto } \\
\text { orgânico }+40 \% \text { sabugo milho, } \\
\text { bagaço cana, cavaco madeira, } \\
\text { folhas, gravetos etc.) }\end{array}$ & $\begin{array}{l}\text { Possibilitar o crescimento de } \\
\text { organismos oxidadores de } \\
\text { amônia e de metano, além de } \\
\text { suprir os nutrientes necessários } \\
\text { para o processo }\end{array}$ \\
\hline & $\begin{array}{c}3 \\
\text { (meio suporte } \\
\text { inorgânico) }\end{array}$ & 30 a 50 & $\begin{array}{l}\text { Mistura homogênea ( } 80 \% \text { brita } \\
\text { de granito, gnaisse ou basalto } \\
\text { de granulometria } 2 \text { e } 3+\text { cavaco } \\
\text { de madeira, sabugo de milho, } \\
\text { ou bagaço de cana) }\end{array}$ & $\begin{array}{l}\text { Possibilitar o crescimento de } \\
\text { organismos oxidadores de } \mathrm{H}_{2} \mathrm{~S} \\
\text { e resistir às condições ácidas } \\
\text { decorrentes da formação de } \\
\text { ácido sulfúrico }\end{array}$ \\
\hline & $\begin{array}{c}2 \\
\text { (camada } \\
\text { drenante) }\end{array}$ & 20 a 30 & $\begin{array}{l}\text { Seixo rolado de sílica com } \\
\text { granulometria } 3 \text { ou } 4 \text { ou brita de } \\
\text { granito, gnaisse ou basalto no } \\
\text { caso de biofiltros estruturados }\end{array}$ & $\begin{array}{l}\text { Possibilitar a drenagem da água } \\
\text { de irrigação e de condensados } \\
\text { da linha de gás }\end{array}$ \\
\hline & $\begin{array}{c}1 \\
\text { (camada } \\
\text { impermeável) }\end{array}$ & - & $\begin{array}{l}\text { Plástico, alvenaria, concreto, } \\
\text { argila compactada, solo- } \\
\text { cimento (terra }+15 \% \text { cimento + } \\
\text { água) }\end{array}$ & $\begin{array}{l}\text { Evitar a percolação de líquido } \\
\text { através do solo }\end{array}$ \\
\hline
\end{tabular}




\section{CONSIDERAÇÕES RELATIVAS AO DIMENSIONAMENTO DE BIOFILTROS}

O dimensionamento de biofiltros é feito com base nos seguintes parâmetros principais (BARBOSA \& STUETZ, 2005; BURGUESS et al., 2001; GOSTELLOW et al., 2008; KENNES \& THALASSO, 1998; WEF, 2004;):

\section{Tempo de contato com o meio suporte}

Para se evitar a introdução de fatores relacionados à porosidade do meio suporte, o tempo de contato com o mesmo é usualmente expresso considerando-se o volume do biofiltro vazio. A literatura especializada recomenda os seguintes tempos de contato para o projeto de biofiltros (WEF, 2004):

- Oxidação de sulfeto de hidrogênio: 15 a 25 segundos

- Oxidação de compostos orgânicos voláteis: 30 a 60 segundos

\section{Taxa de aplicação superficial}

A taxa de aplicação superficial refere-se à vazão de gases admitidos (contendo os gases residuais e o ar de diluição) aplicada à superfície do meio suporte, devendo ser verificada considerando a vazão nominal de ar do equipamento de exaustão. A literatura especializada recomenda taxas de aplicação entre 60 e $100 \mathrm{~m}^{3} \cdot \mathrm{m}^{-2} \cdot \mathrm{h}^{-1}$.

Conhecendo-se o volume de meio suporte necessário para o biofiltro (determinado com base no tempo de contato com o meio suporte) e a espessura da camada de meio suporte (adotada conforme faixa especificada no Quadro 1), pode-se estabelecer a área superficial do biofiltro e verificar a taxa de aplicação superficial.

\section{Carga volumétrica}

A carga volumétrica refere-se à massa de composto odorante aplicada ao volume de meio suporte. No caso particular de biofiltros aplicados ao tratamento de gases odorantes emitidos em reatores anaeróbios tratando esgoto doméstico, o composto odorante de maior importância para o projeto é o $\mathrm{H}_{2} \mathrm{~S}$, uma vez que o nitrogênio e os compostos orgânicos voláteis são uma preocupação secundária (Gostelow, et al., 2001). Dessa forma, torna-se importante estimar a carga de $\mathrm{H}_{2} \mathrm{~S}$ passível de emissão pelos reatores, de modo a possibilitar a verificação da carga volumétrica aplicada à camada de meio suporte inorgânico do biofiltro (camada 3 - Quadro 1). As cargas volumétricas aplicadas a esta camada situam-se usualmente entre 0,46 e 3,22 kg $\mathrm{H}_{2} \mathrm{~S}-\mathrm{S} \cdot \mathrm{m}^{-3} \cdot \mathrm{d}^{-\mathbf{1}}$.

Com base em tais critérios e parâmetros de dimensionamento, é possível estabelecer as dimensões do biofiltro, desde que sejam estimadas as concentrações dos compostos odorantes (particularmente de $\mathrm{H}_{2} \mathrm{~S}$ ) nos gases residuais e a vazão da mistura ar + gás residual a ser encaminhada para o biofiltro. Para o completo dimensionamento do biofiltro são necessários os seguintes dados de entrada e a seguinte seqüência de cálculos:

\begin{tabular}{|c|c|c|}
\hline Dados de entrada & Valores típicos & \multirow{8}{*}{ 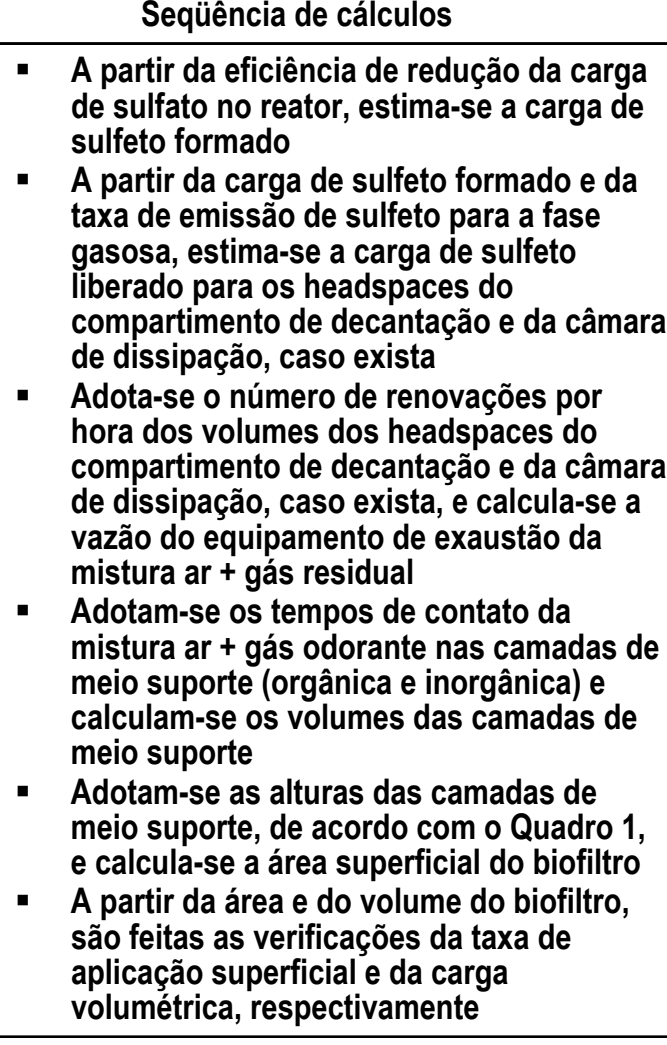 } \\
\hline $\begin{array}{l}\text { - Vazão média de esgoto afluente } \\
\text { ao reator }\end{array}$ & - & \\
\hline $\begin{array}{l}\text { - Eficiência de redução de sulfato } \\
\text { a sulfeto no reator }\end{array}$ & 70 a $80 \%(1)$ & \\
\hline $\begin{array}{l}\text { - Taxa de emissão de sulfeto no } \\
\text { compartimento de decantação }\end{array}$ & 3,5 a $18,5 \mathrm{mgH}_{2} \mathrm{~S}-\mathrm{S}$. gH $2 \mathrm{~S}-\mathrm{S}$-efl.-1(1) & \\
\hline $\begin{array}{l}\text { Taxa de emissão de sulfeto em } \\
\text { câmara de dissipação }\end{array}$ & 65 a 130 mgH$_{2} \mathrm{~S}-\mathrm{S}$. gH ${ }_{2}$ S-S-efl. ${ }^{-1(1))}$ & \\
\hline $\begin{array}{l}\text { Volumes dos headspaces do } \\
\text { compartimento de decantação e } \\
\text { do headspace da câmara de } \\
\text { dissipação, caso exista }\end{array}$ & - & \\
\hline $\begin{array}{l}\text { Número de renovações dos } \\
\text { volumes dos headspaces do } \\
\text { compartimento de decantação e } \\
\text { da câmara de dissipação, caso } \\
\text { exista }\end{array}$ & 4 a 6 renovações. $h^{-1}(2,3)$ & \\
\hline $\begin{array}{l}\text { Tempo de contato da mistura ar } \\
\text { + gás residual na camada de } \\
\text { meio suporte do biofiltro }\end{array}$ & $\begin{array}{l}\left.15 \text { a } 25 \text { s (para } \mathrm{H}_{2} \mathrm{~S}\right)^{(2)} \\
30 \text { a } 60 \mathrm{~s}(\text { para COV) }\end{array}$ & \\
\hline
\end{tabular}

(1) Valores obtidos em reatores UASB tratando esgoto sanitário típico, operado nas faixas de pH entre 6,6 e 7,0 e temperatura do esgoto entre 22 e $25^{\circ} \mathrm{C}$.

(2) Valores típicos obtidos a partir da literatura especializada

(3) 4 a 6 renovações por hora para espaços não visitáveis, e 12 renovações por hora para espaços visitáveis por operadores 
Naturalmente que estas taxas de emissão de sulfeto são significativamente influenciadas pelas condições de pH. Segundo cálculos desenvolvidos a partir do que foi estabelecido por Hvitved-Jacobsen (2002), para condição de equilíbrio, a influência de uma variação do $\mathrm{pH}$ de 0,5 para mais, relativamente ao valor médio encontrado de 6,8 , diminui a concentração de sulfeto no headspace e, consequientemente, a taxa de emissão, em $45 \%$. Por sua vez, uma variação de 0,5 no $\mathrm{pH}$ para menos, relativamente ao $\mathrm{pH}$ médio de 6,8 , aumenta a concentração e a taxa de emissão de sulfeto em $36 \%$.

Contudo, tal condição de equilíbrio possivelmente não se verifique na prática, seja para condições relativamente mal ventiladas, como as de uma tubulação de esgotamento sanitário (Matos e Aires, 1995), seja para condições bem ventiladas, como as que se desenvolvem em situações de exaustão de uma atmosfera gasosa. Todavia, ainda assim é possível se considerar a influência do $\mathrm{pH}$ nas proporções mencionadas no parágrafo anterior, uma vez que o abaixamento do $\mathrm{pH}$ provoca o deslocamento do equilíbrio e a formação do $\mathrm{H}_{2} \mathrm{~S}$ molecular, que é a forma volátil deste composto.

\section{CONSIDERAÇÕES FINAIS}

Com esta nota técnica, espera-se contribuir para o maior entendimento da problemática de geração e de controle de emissões odorantes em estações de tratamento de esgoto que utilizam reatores anaeróbios, notadamente na modalidade de reatores UASB.

A ênfase no tratamento biológico das emissões gasosas por biofiltros se deve à grande aplicabilidade desse método para a remoção de $\mathrm{H}_{2} \mathrm{~S}$, que se constitui no principal composto potencialmente causador de odor em reatores anaeróbios. Ademais, dentre os métodos disponíveis, os biofiltros são os que agregam as maiores vantagens em termos de simplicidade, sustentabilidade e baixos custos de construção e de operação. Finalmente, espera-se que a sistematização das principais diretrizes para o projeto de biofiltros possa auxiliar na maior difusão desse método de tratamento de emissões odorantes no Brasil, e também contribuir para a melhoria do projeto e da operação de reatores UASB aplicados ao tratamento de esgoto doméstico.

\section{AGRADECIMENTOS}

Os autores agradecem o apoio recebido do Conselho Nacional de Desenvolvimento Científico e Tecnológico - CNPq.

\section{REFERÊNCIAS}

BARBOSA V.L \& STUETZ R.M. Treatment of hydrogen sulfide in biofuels. In.: Lens, P., Westermann P., Haberbauer M. and Moreno A. (editors) (2005). Biofuels for fuel cells: renewable energy from biomass fermentation. Chapter 23. IWA Publishing, London, 524 p., 2005.
BURGESS, J.E., PARSONS, S.A. and STUETZ, R.M. 'Developments in odour control and waste gas treatment biotechnology: a review'. Biotechnology Advances, 19 (1): 35-63, 2001.

CHERNICHARO, C.A.L. and STUETZ, R.M. 'Improving the design and operation of UASB reactors for treating domestic wastewater: management of gaseous emissions'. IX Latin American Workshop and Seminar on Anaerobic Digestion. Eastern Island - Chile: IWA, 2008.

CHERNICHARO, C.A.L., STUETZ, R.M., SOUZA, C.L., MELO, G.C.B. Alternativas para o controle de emissões odorantes em reatores anaeróbios tratando esgoto doméstico. Engenharia Sanitária e Ambiental, 15 (3): 229-236, 2010.

GOSTELLOW, P., ROBINSON, T., LONGHURST, P., LOVELL, M., BARTON, M., WINTER, P., CRANSHAW, I., THOMPSON, A., STUETZ, R.M. and JEFFERSON, B. 'Design, operation and performance considerations for the selection of odour abatement technologies in sewage treatment works (STW)', 2008.

HVITVED-JACOBSEN, T. Sewer Processes - Microbial and Chemical Process Engineering of Sewer Networks. CRC Press, Florida, USA, 2002.

KENNES, C. and THALASSO, F. 'Waste gas biotreatment technology'. J. Chem. Technol. Biotechnol., 72:303-319, 1998.

KENNES, C., VEIGA, M.C. and PRADO, O. 'Non biological treatment technologies'. In: Kennes, C. and Veiga, M.C. (eds). Bioreactors for waste gas treatment. Dordrecht: Kluwer Academic Publishers, 2001.

MATOS, J.S. and AIRES, C. M. Mathematical modelling of sulphides and hydrogen sulfphide gas build-up in tehe cosas do estoril sewerage system. Water Science and Technology. 31 (7): 255-261, 1995

STUETZ, R.M. and FRECHEN, F.-B. Odours in wastewater treatment: measurement, modelling and control. London: IWA Publishing, 2001.

VAN GROENESTIJN, J.W. and HESSELINK, P.G.M. 'Biotechniques for air pollution control'. Biodegradation, 4:283-301, 1993.

WEF. Control of odors and emissions from wastewater treatment plants - Manual of Practice 25. Alexandria: Water Environment Federation, 538 p., 2004. 